\title{
Etoposide induces a mixed type of programmed cell death and overcomes the resistance conferred by Bcl-2 in Hep3B hepatoma cells
}

\author{
SEUNG HEE YOO ${ }^{1}$, YOUNG GEOL YOON ${ }^{1,5}$, JEE SUK LEE ${ }^{1}$, YEON SUK SONG ${ }^{1}$, JOON SEOK OH ${ }^{1}$, \\ BONG SOO PARK ${ }^{2}$, TAEG KYU KWON ${ }^{3}$, CHEOL PARK $^{4}$, YUNG HYUN CHOI ${ }^{4}$ and YOUNG HYUN YOO ${ }^{1}$ \\ ${ }^{1}$ Department of Anatomy and Cell Biology and Mitochondria Hub Regulation Center, College of Medicine, \\ Dong-A University; ${ }^{2}$ College of Dentistry and Research Institute for Oral Biotechnology, Pusan National University, Busan; \\ ${ }^{3}$ Department of Immunology, School of Medicine, Keimyung University, Taegu; ${ }^{4}$ Department of Biochemistry and \\ Research Institute of Oriental Medicine, Dongeui University College of Oriental Medicine, Busan, Republic of Korea
}

Received May 16, 2012; Accepted July 13, 2012

DOI: $10.3892 /$ ijo.2012.1585

\begin{abstract}
The Bcl-2 protein is known to exert not only antiapoptotic but also anti-autophagic activities. Numerous studies have demonstrated that etoposide, which is one of the most widely used cancer chemotherapy agents, induces apoptotic cell death. However, the exact molecular mechanism leading to cell death by etoposide remains to be resolved. This study aimed to dissect the mode of cell death induced by etoposide in Hep3B hepatoma cells. Furthermore, this study was conducted to examine whether etoposide overcomes the resistance conferred by Bcl-2 in Hep3B hepatoma cells. We observed that Hep3B cells treated with etoposide show not only apoptotic but autophagic phenotypes. Autophagy inhibition by 3-methyladenine (3MA) and caspase inhibition by zVAD-fmk effectively decreased autophagic and apoptotic phenotypes, respectively. However, either zVAD-fmk or 3MA only partially prevented cell death. These data indicate that etoposide concomitantly induces autophagic cell death and apoptosis in Hep3B cells. Importantly, etoposide can effectively induce cell death in Bcl-2-overexpressing Hep3B cells. Conversely, staurosporine, which exclusively induces apoptosis in Hep3B cells, did not efficiently induce cell death in Bcl-2-overexpressing Hep3B cells. Staurosporine-treated Hep3B cells also showed an autophagic phenotype. While autophagy is cell death-inducing in Hep3B cells treated with etoposide, it is cytoprotective in Hep3B cells treated with staurosporine. To this end, we observed that
\end{abstract}

Correspondence to: Dr Young Hyun Yoo, Department of Anatomy and Cell Biology, Dong-A University College of Medicine, 3-1 Dongdaeshin-dong, Seo-gu, Busan 602-714, Republic of Korea E-mail: yhyoo@dau.ac.kr

Present address: ${ }^{5}$ Department of Biomedical Science, Institute for Biomedical and Health Sciences, Jungwon University, Goesan-eup, Goesan-gun, Chungbuk, Republic of Korea

Key words: Hep3B hepatoma, Bcl-2, apoptosis, autophagy, etoposide etoposide-induced mixed type of programmed cell death is associated with the dissociation of Bcl-2 from Beclin-1. Taken together, etoposide induces a mixed type of programmed cell death and overcomes the resistance conferred by Bcl-2 in Hep3B hepatoma cells.

\section{Introduction}

Despite the large number of studies in this field, controversies regarding the definition of cell death and the classification of cell death types have not yet been resolved. Based on morphological criteria, three types of cell death have been defined: apoptosis, autophagic cell death and necrosis. Apoptosis (programmed cell death-type I, PCD-type I) and necrosis are well-known mechanisms of cell death induced by several stimuli. Emerging studies have demonstrated the existence of a nonapoptotic form of programmed cell death called autophagic cell death (programmed cell death-type II, PCD-type II). However, the clear-cut distinctions among these three types of cell death are still controversial, and a clear equivalence between the ultrastructural alterations and biochemical cell death characteristics has not been established (1).

All Bcl-2 family members contain at least one of the four conserved $\alpha$-helical motifs known as Bcl-2 homology (BH) domains (BH1-BH4) (2). Bcl-2 family members are grouped into three categories: the anti-apoptotic members, including Bcl-2, Bcl-xL and Mcl-1; the multidomain proapoptotic members, such as Bax and Bak; and the BH3 domain only proteins, such as Bim, Bid, Bad and Bik (3). Bcl-2 family members are known to regulate apoptosis. Although Bcl-2 family proteins have been found to have diverse subcellular locations, the principal site in which the action of apoptosis is regulated by $\mathrm{Bcl}-2$ family proteins is likely the mitochondrial membrane. The anti-apoptotic multidomain proteins (Bcl-2, Bcl-xL, Bcl-w and Mcl-1) mainly reside in the mitochondria. The anti-apoptotic Bcl-2 family members prevent the translocation and/or activation of Bax-like proteins in the mitochondria (4), inhibiting cytochrome $c$ release from the mitochondria or mitochondrial membrane depolarization. 
Certain members of the Bcl-2 family are present on the endoplasmic reticulum (ER), where they participate in regulating ER-mediated apoptosis (5).

Previous studies have elucidated that Bcl-2 inhibits autophagy. Antisense knockdown of Bcl-2 in HL-60-induced autophagy (6), and Bcl-2 gene silencing increase autophagy, and $\mathrm{Bcl}-2$ transgenic expression reduces the level of starvationinduced autophagy. Furthermore, the study using Bcl-2 mutants restricting subcellular localization showed that $\mathrm{Bcl}-2$ functions at the ER and not at the mitochondria to inhibit starvation-induced autophagy (7). Thus, Bcl-2 not only functions as an anti-apoptotic protein but also as an anti-autophagic factor. Increasing data suggest that $\mathrm{Bcl}-2$ plays a pivotal role in modulating the complex interaction that exists between autophagy and the apoptotic cell death pathway. Bcl-2 is known to interact with the evolutionarily conserved autophagy protein, Beclin-1 protein, which is part of a Class III PI3K complex that participates in autophagosome formation, mediating the localization of other autophagy proteins to the preautophagosomal membrane (8). $\mathrm{Bcl}-2$ overexpression interferes with the formation of the autophagy-promoting Beclin-1/hVps34 complex (7).

The resistance of tumor cells to the current chemotherapeutic drugs is a challenging hurdle to cancer treatment. Upregulation of the anti-apoptotic molecules in tumors impairs remission and cure with chemotherapy, protecting the tumor cells from the apoptotic effects of various antineoplastic agents. High expression of the anti-apoptotic protein $\mathrm{Bcl}-2$ is found in numerous human tumors (9). Anti-apoptotic Bcl-2 proteins inhibit apoptosis induced by various stimuli including chemotherapeutics (10). The functional blockade of $\mathrm{Bcl}-2$ or other anti-apoptotic proteins, such as Bcl-xL, could either induce apoptosis in cancer cells or sensitize these cells to chemotherapy (11). Because anti-apoptotic factors, including Bcl-2, impair the ability to achieve remission and cure with chemotherapy, protecting the tumor cells from the apoptotic effects of various antineoplastic agents, anti-apoptotic members of the Bcl-2 family have attracted interest in drug discovery to develop a new class of anticancer agents.

Etoposide (VP-16) is a semi-synthetic derivative of podophyllotoxin and acts as a topoisomerase II inhibitor by forming a ternary complex. Etoposide, which is one of the most widely used cancer chemotherapy agents (12), has been used clinically both as a single agent and a constituent of combination chemotherapy regimens and is known to improve the treatment of various human cancers (13). Numerous studies have demonstrated that etoposide induces apoptotic cell death. However, the exact molecular mechanism leading to apoptotic cell death by etoposide remains to be elucidated.

This study examined whether etoposide overcomes the resistance conferred by Bcl-2 in Hep3B hepatoma cells. We found that etoposide overcomes the resistance conferred by Bcl-2 in Hep3B hepatoma cells via the induction of autophagic cell death.

\section{Materials and methods}

Reagents and antibodies. The following reagents were obtained commercially: rabbit polyclonal anti-human Bcl-2, Beclin-1, retinoblastoma protein (pRB), p130, E2F1, E2F4, cyclin D1, cyclin E, cyclin-dependent kinases (Cdk2, Cdk4 and Cdk6) and goat polyclonal anti-human MAP LC $3 \beta$ and mouse monoclonal anti-human cyclin A antibodies from Santa Cruz Biotechnology
(Santa Cruz, CA, USA); rabbit polyclonal anti-human caspase-3, caspase-6, caspase-7 and SQSTM1/p62, mouse monoclonal anti-human caspase-9 antibodies, HRP-conjugated goat antirabbit and horse anti-mouse IgGs from Cell Signaling (Danvers, MA, USA); mouse monoclonal anti-human $\beta$-actin antibody, Hoechst 33342, dimethyl sulfoxide (DMSO), propidium iodide (PI), staurosporine, acridine orange, monodansylcadaverine, 3-methyladenine (3MA), and Annexin V-FITC apoptosis detection kit from Sigma-Aldrich (Irvine, CA, USA); caspase inhibitor I zVAD-fmk and neomycin sulfate (G418), mouse monoclonal anti-human p27, p21, p16 antibodies and necrostatin-1 from Calbiochem (San Diego, CA, USA); 3,3'-dihexyloxacarbocyanine iodide $\left(\mathrm{DiOC}_{6}\right)$ from Molecular Probes (Eugene, OR, USA); SuperSignal West Pico enhanced chemiluminescence western blot detection reagent from Pierce (Rockford, IL, USA); RNase A and proteinase K from Biosesang (Sungnam, Korea); etoposide (VP-16) from Nippon Kayaku (Tokyo, Japan); siPORT Amine was from Ambion (Austin, TX, USA); Lipofectamine was from Invitrogen (Calsbad, CA, USA).

Cells. Hep3B cells were obtained from the American Type Culture Collection (ATCC HB-8064; Rockville, MD, USA).

Cell culture and establishment of Hep3B/Bcl-2 cells. Hep3B cells were cultured in complete Dulbecco's modified Eagle's medium (DMEM; Gibco, Gaithersburg, MD) supplemented with $10 \%$ heat-inactivated fetal bovine serum (FBS; Gibco) and $100 \mathrm{U} / \mathrm{ml}$ penicillin in $5 \% \mathrm{CO}_{2}$ at $37^{\circ} \mathrm{C}$. Mammalian expression vector encoding Flag-tagged $\mathrm{Bcl}-2$ was kindly provided by Professor A. Strasser (The Walter and Eliza Hall Institute of Medical Research, Melbourne, Australia). Hep3B cells were transfected with the expression vector encoding Flag-tagged Bcl-2 using FuGENE6 reagent (Roche, Mannheim, Germany) according to the manufacturer's instructions. The transfected cells were incubated for two days, and stable cells were then selected with changes of fresh medium containing puromycin ( $4 \mu \mathrm{g} / \mathrm{ml}$ ) for four weeks. Single-cell clones were isolated by limiting dilutions and subsequently analyzed for an increase of Bcl-2 expression relative to identically cloned empty vector controls.

Treatment with etoposide and other pharmacological agents. Forty-eight hours after Hep3B/vec and Hep3B/Bcl-2 cells were cultured, the original medium was removed. Cells were washed with PBS and then incubated in the same fresh medium. Etoposide and staurosporine were stocked in DMSO. Etoposide from a stock solution was added to the medium to obtain indicated dilutions $(0-70 \mu \mathrm{g} / \mathrm{ml})$ of the drug for 0-48 h. Staurosporine from a stock solution was added to the medium to obtain indicated dilutions $(0-500 \mathrm{nM})$ of the drug for 0-48 h. The concentration of DMSO used in this study had no effect on Hep3B/vec and $\mathrm{Hep} 3 \mathrm{~B} / \mathrm{Bcl}-2$ cells proliferation in our preliminary studies. To examine the effect of caspase or autophagy inhibitor, cells were incubated in the presence or absence of $100 \mu \mathrm{M} z V A D-f m k$ or $1 \mathrm{mM} 3 \mathrm{MA}$ for $3 \mathrm{~h}$. Cells then exposed to $40 \mu \mathrm{g} / \mathrm{ml}$ etoposide or $300 \mathrm{nM}$ staurosporine for $48 \mathrm{~h}$.

Cell viability assay. Cell viability was determined by the Vi-Cell cell counter (Beckman Coulter, Miami, FL, USA), which performs an automated trypan blue exclusion assay. 
Nuclear morphology. Cell suspensions were cytospun onto clean fat-free glass slides using a cytocentrifuge. Centrifuged samples were fixed in $4 \%$ paraformaldehyde for $10 \mathrm{~min}$ and stained in $4 \mu \mathrm{g} / \mathrm{ml}$ Hoechst 33342 for $30 \mathrm{~min}$ at $37^{\circ} \mathrm{C}$. Cells were observed and photographed under an epifluorescence microscope by an observer who was blinded to the experimental group.

Quantification of DNA hypoploidy and cell cycle phase analysis by flow cytometry. Ice-cold $95 \%$ ethanol with $0.5 \%$ Tween-20 was added to cell suspensions to a final concentration of $70 \%$ ethanol. Fixed cells were pelleted and washed with PBS containing $1 \%$ bovine serum albumin (BSA). Cells were resuspended in $1 \mathrm{ml}$ PBS containing 11 Kunitz U/ml RNase, incubated at $4^{\circ} \mathrm{C}$ for $30 \mathrm{~min}$, washed once with BSA-PBS and resuspended in PI solution $(50 \mu \mathrm{g} / \mathrm{ml})$. After the cells had been incubated at $4^{\circ} \mathrm{C}$ for $30 \mathrm{~min}$ in the dark and washed with PBS, DNA content was measured using Epics XL (Beckman Coulter), and the data were analyzed using the Multicycle software which allowed a simultaneous estimation of cell cycle parameters and apoptosis.

Western blot analysis. Cells $\left(2 \times 10^{6}\right)$ were washed twice with ice-cold PBS, resuspended in RIPA buffer (Elpis Biotech, Daejeon, Korea) and incubated at $4^{\circ} \mathrm{C}$ for $30 \mathrm{~min}$. The lysates were centrifuged at $14,000 \mathrm{rpm}$ for $20 \mathrm{~min}$ at $4^{\circ} \mathrm{C}$. Protein concentrations of cell lysates were determined with Bradford protein assay reagent (Bio-Rad) and $30 \mu \mathrm{g}$ of proteins were loaded onto 7.5-15\% SDS-PAGE. The gels were transferred to nitrocellulose membrane (Amersham Pharmacia Biotech, Piscataway, NJ, USA) and reacted with each antibody. Immunostaining with antibodies was performed using the Super Signal West Pico enhanced chemiluminescence substrate and detected with LAS-4000PLUS (Fuji Photo Film Company, Kanagawa, Japan).

Transfection of GFP-LC3 in Hep3B/vec and Hep3B/Bcl-2 cells and confocal microscopy. Hep3B/vec and Hep3B/Bcl-2 cells plated in six-well dishes were transfected with $4 \mu \mathrm{g}$ of LC3 cDNA using Lipofectamine reagent (Invitrogen, Calsbad, CA, USA). The mammalian expression construct of human LC3 cloned into pEGFP was a gift from Dr N. Mizushima (Tokyo Medical and Dental University, Tokyo, Japan). An empty pEGFP vector was used as a control for the stable expression of LC3. Stable transfectants of Hep3B/vec and Hep3B/Bcl-2 cells were selected with changes in medium containing $400 \mu \mathrm{g} / \mathrm{ml}$ of G418. Cells grown in coverslides were treated as indicated and fixed with $4 \%$ paraformaldehyde for $10 \mathrm{~min}$. Fluorescent images were observed and analyzed under Zeiss LSM 700 laserscanning confocal microscope (Göettingen, Germany).

Transmission electron microscopy. Forty-eight hours after treatment, cells were harvested, pelleted and fixed in $2.5 \%$ glutaraldehyde (Sigma-Aldrich) in phosphate buffer. After rinsing with phosphate buffer, the samples were postfixed in $1 \%$ osmium tetroxide (Sigma-Aldrich) for $1 \mathrm{~h}$, rinsed with water, dehydrated in a graded series of ethanol followed by propylene oxide (Sigma-Aldrich) and kept overnight in Epon812 (Sigma-Aldrich). The samples were embedded in Epon812 and cured in an oven at $60^{\circ} \mathrm{C}$. Ultrathin sections were obtained with a Reichert Ultracut $\mathrm{E}$ microtome. The sections were stained with uranyl acetate and lead citrate and observed using an $\mathrm{H} 7650$ transmission electron microscope (Hitachi, Tokyo, Japan).

Detection of autophagosome formation with acridine orange and monodansylcadaverine (MDC) by flow cytometry. Cells were seeded on 6 -well plates $\left(1 \times 10^{5}\right.$ cells $\left./ \mathrm{ml}\right)$. After $24 \mathrm{~h}$ of incubation, cells were treated with etoposide and staurosporine, and cultured for $48 \mathrm{~h}$. Cells were trypsinized, collected, and stained with acridine orange (final concentration of $1 \mu \mathrm{g} / \mathrm{ml}$ ) or MDC (final concentration of $50 \mu \mathrm{M}$ ) for $10 \mathrm{~min}$ at $37^{\circ} \mathrm{C}$. After centrifugation, cells were resuspended in PBS and analyzed with Epics XL.

Flow cytometric analysis of Annexin V-FITC binding for apoptosis. Apoptosis was determined by flow cytometry with the Annexin V-FITC apoptosis detection kit according to the manufacturer's instruction. Cells were incubated with etoposide and staurosporine for $48 \mathrm{~h}$. The cells were collected, centrifuged, and resuspended in binding buffer, and incubated with Annexin V-FITC and PI for $20 \mathrm{~min}$ at room temperature in the dark. After double staining, the cells were analyzed with Epics XL.

DNA electrophoresis. Cells $\left(0.6 \times 10^{6}\right)$ were resuspended in $1.5 \mathrm{ml}$ of lysis buffer (10 mM Tris-HCl, $10 \mathrm{mM}$ EDTA, $10 \mathrm{mM} \mathrm{NaCl}$, $0.5 \%$ SDS, pH 7.5) into which proteinase $\mathrm{K}(200 \mu \mathrm{g} / \mathrm{ml})$ was added. After samples were incubated overnight at $48^{\circ} \mathrm{C}, 200 \mu \mathrm{l}$ of ice cold $5 \mathrm{M} \mathrm{NaCl}$ was added and the supernatant containing fragmented DNA was collected after centrifugation. The DNA was then precipitated overnight at $-20^{\circ} \mathrm{C}$ in $50 \%$ isopropanol and RNase A-treated for $1 \mathrm{~h}$ at $37^{\circ} \mathrm{C}$. The DNA from $1 \times 10^{6}$ or $2 \times 10^{6}$ cells $(15 \mathrm{ml})$ was equally loaded on each lane of $2 \%$ agarose gels in Tris-acetic acid/EDTA buffer containing $0.5 \mu \mathrm{g} / \mathrm{ml}$ ethidium bromide at $50 \mathrm{~mA}$ for $1.5 \mathrm{~h}$.

Pulsed-field gel electrophoresis (PFGE). For PFGE, cells $\left(2 \times 10^{6}\right)$ were suspended in $50 \mu \mathrm{l}$ of PBS and mixed with $50 \mu \mathrm{l}$ of PBS containing $1 \%$ low melting temperature agarose. The cell suspension was poured into a template $(5 \times 2 \times 10 \mathrm{~mm})$, plugged, and cooled on ice. The hardened agarose gel blocks were incubated with $250 \mu \mathrm{l}$ of a mixture of proteinase $\mathrm{K}(1 \mathrm{mg} / \mathrm{ml})$, N-lauroyl sarcosine sodium (1\% w/v), and 0.5 M EDTA (pH 9.2) at $50^{\circ} \mathrm{C}$ for $48 \mathrm{~h}$. After incubation, half the volume of the digested agarose gel block was loaded into a sample well of a $1 \%(\mathrm{w} / \mathrm{v})$ agarose gel (Sigma type II, $150 \times 150 \times 4.4 \mathrm{~mm}$ ) in $0.5 \mathrm{X}$ TBE buffer (89 mM Tris-boric acid, $2 \mathrm{mM}$ EDTA, pH 8.0). The PFGE apparatus used was the Gene Path System from Bio-Rad. PFGE was carried out in $0.5 \mathrm{X}$ TBE maintained at $14^{\circ} \mathrm{C}$ by circulating cool water for $16 \mathrm{~h}$ (constant, $6 \mathrm{~V}$; switch times are initial $60 \mathrm{sec}$ and final $90 \mathrm{sec}$ ). DNA in the gel was stained with ethidium bromide and detected with LAS-4000Plus (Fuji Photo Film Company, Kanagawa, Japan). Chromosomal DNA from Saccharomyces cerevisiae (from Bio-Rad), a mixture of $\lambda$ DNA, its concatemers, and HindIII-digested $\lambda$ DNA (from Sigma-Aldrich) were used as DNA size markers.

Beclin-1 small interfering RNA (siRNA) transfection and combination treatment with etoposide or staurosporine. Transfection of siRNA against Beclin-1 transcripts was performed by using siPORT Amine (Ambion, Austin, TX, USA) in Opti-MEM 

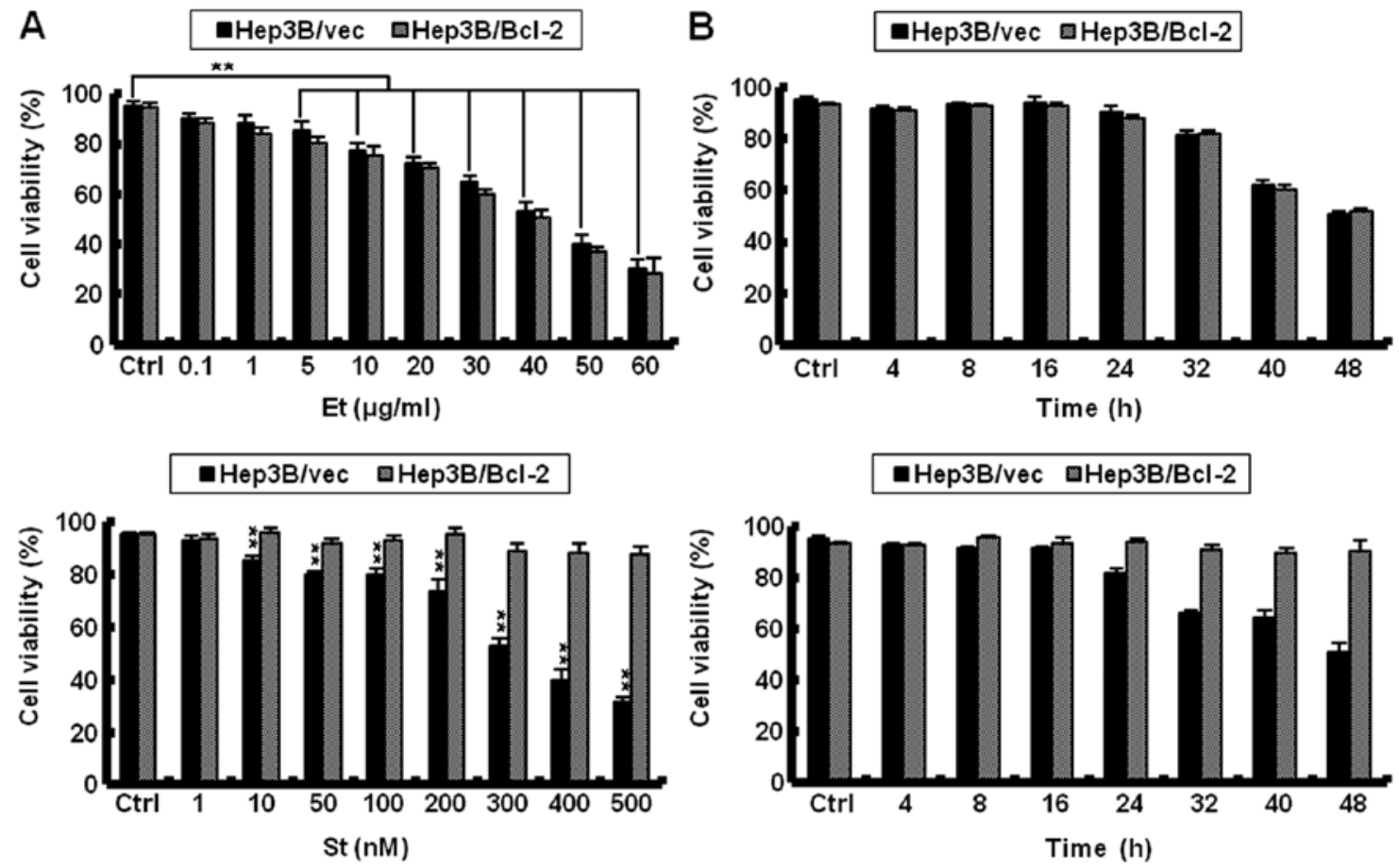

Figure 1. Etoposide, but not staurosporine, bypasses the chemoresistance conferred by Bcl-2 in Hep3B cells. Ctrl, control; Et, etoposide; St, staurosporine; Hep3B/ vec, Hep3B cells transfected with empty vector; Hep3B/Bcl-2, Bcl-2-overexpressing Hep3B cells. Four independent assays were performed, and the data are shown as the mean \pm SD obtained from triplicates of each experiment. (A) Reduction in viability after treatment with etoposide or staurosporine at various doses. Etoposide at $5-60 \mu \mathrm{g} / \mathrm{ml}$ significantly reduced the viability of both Hep3B/vec and Hep3B/Bcl-2 cells. Staurosporine at $10-500 \mathrm{nM}$ significantly reduced the viability of Hep3B/ vec but not Hep3B/Bcl-2 cells. ${ }^{* *} \mathrm{p}<0.01$. (B) The reduction in viability after treatment with etoposide or staurosporine at various time points. Etoposide at $40 \mu \mathrm{g} / \mathrm{ml}$ reduced the viability of both $\mathrm{Hep} 3 \mathrm{~B} / \mathrm{vec}$ and $\mathrm{Hep} 3 \mathrm{~B} / \mathrm{Bcl}-2$ cells in a time-dependent manner. Staurosporine at $300 \mathrm{nM}$ for $48 \mathrm{~h}$ reduced the viability of Hep3B/vec but not $\mathrm{Hep} 3 \mathrm{~B} / \mathrm{Bcl}-2$ cells in a time-dependent manner.

(GibcoBRL) media according to manufacturer's recommendations. Beclin-1 siRNA was purchased from Cell signaling. Cells were treated with etoposide and staurosporine for $48 \mathrm{~h}$.

Co-immunoprecipitation (Co-IP). Cell extracts that were incubated with antibodies were precipitated with protein A-Sepharose beads. Immunoprecipitated proteins were separated on SDS-PAGE, and western blot analysis was performed as described.

Statistical analysis. Four independent experiments were carried out in vitro. The results are expressed as means \pm SD from four experiments, each performed in triplicate. The results of the experimental and control groups were tested for statistical significance by the nonparametric Kruskall-Wallis test. In all cases, a p-value $<0.05$ was considered significant.

\section{Results}

Etoposide, but not staurosporine, bypasses the chemoresistance conferred by Bcl-2 in Hep3B cells. Etoposide at 5-60 $\mu \mathrm{g} / \mathrm{ml}$ significantly reduced the viability of Hep3B cells compared to the control Hep3B cells. Noticeably, etoposide at the same doses also significantly reduced the viability in Bcl-2-overexpressing Hep3B cells, indicating that etoposide bypasses the chemoresistance conferred by Bcl-2 in Hep3B cells. Another representative apoptosis inducer staurosporine at $10-500 \mathrm{nM}$ also significantly reduced the viability of Hep3B cells in a dose-dependent manner. However, staurosporine at the same doses did not significantly reduce viability in Bcl-2-overexpressing Hep3B cells, indicating that staurosporine does not bypass the chemoresistance conferred by Bcl-2 in Hep3B cells (Fig. 1A). Because the viability of $\mathrm{Hep} 3 \mathrm{~B} / \mathrm{vec}$ cells treated with $40 \mu \mathrm{g} / \mathrm{ml}$ etoposide or $300 \mathrm{nM}$ staurosporine for $48 \mathrm{~h}$ was approximately $50 \%$, this single concentration was utilized for further study. Etoposide at $40 \mu \mathrm{g} / \mathrm{ml}$ reduced the viability of $\mathrm{Hep} 3 \mathrm{~B} / \mathrm{Bcl}-2$ and $\mathrm{Hep} 3 \mathrm{~B} / \mathrm{vec}$ cells in a time-dependent manner. Staurosporine at $300 \mathrm{nM}$ for $48 \mathrm{~h}$ reduced the viability of Hep3B/vec cells in a time-dependent manner. However, ectopic expression of $\mathrm{Bcl}-2$ prevented the reduction in viability by staurosporine in Hep3B cells (Fig. 1B).

Etoposide induces $G_{I} / S$ phase arrest in $H e p 3 B / v e c$ and $\mathrm{Hep} 3 \mathrm{~B} / \mathrm{Bcl}-2$ cells. Analysis via a flow cytometric method, which allows the simultaneous estimation of cell cycle parameters and apoptosis, elucidated not only the rate at which etoposide altered cell cycle progression but also the correlation between cell cycle progression and cell death. Time-course analysis of cell cycle distribution after etoposide treatment revealed an increase in the percentage of S-phase cells and also a sustained increase in the S-phase population, while producing a concomitant fall in the percentage of $\mathrm{G}_{0} / \mathrm{G}_{1}$ phase cells. The increase in the S-phase cell percentage and decrease in the $\mathrm{G}_{0} / \mathrm{G}_{1}$ phase populations paralleled an increase in the subG $\mathrm{G}_{1}$ portion. In contrast to etoposide, staurosporine treatment revealed an increase in the percentage of $\mathrm{G}_{2} / \mathrm{M}$-phase cells, while producing a concomitant fall in the percentage of $G_{0} / G_{1}$ phase cells. The increase in the $G_{2} / M$ phase cell percentage and concomitant fall in the percentage of $\mathrm{G}_{0} / \mathrm{G}_{1}$ phase cells paralleled an increase in the subG $\mathrm{G}_{1}$ portion 
A

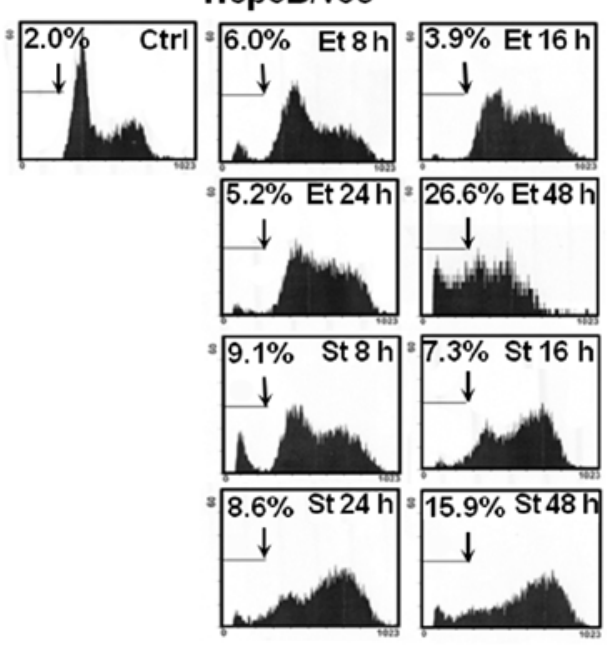

Hep3B/Bcl-2

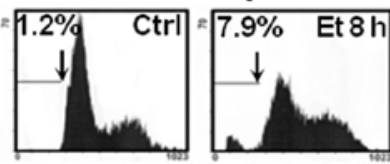

$5.1 \%$ Et $24 \mathrm{~h}$

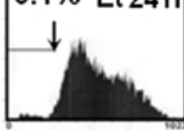

$6.0 \%$ St $8 \mathrm{~h}$

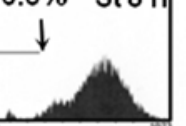

$9.6 \%$ St $24 h$

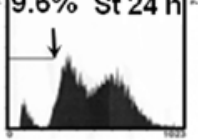

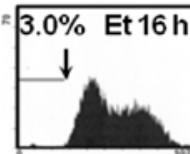

$15.1 \%$ Et $48 \mathrm{~h}$
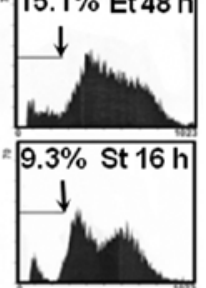

$9.2 \%$ St $48 \mathrm{~h}$

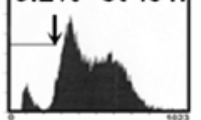

B

Hep3B/vec - Et

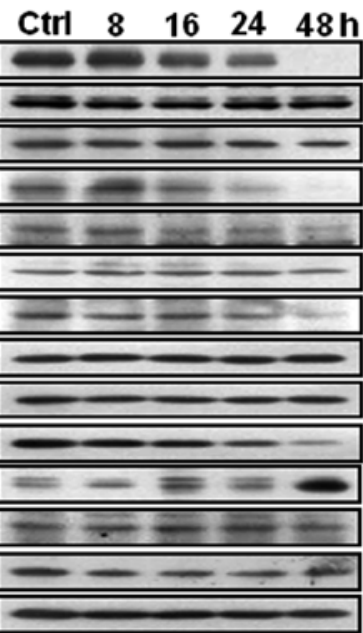

Hep3B/vec-St

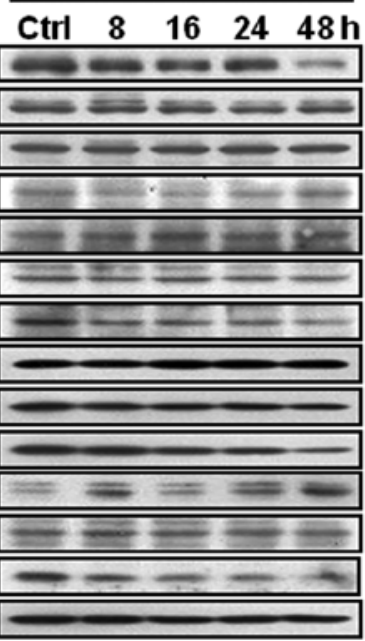

Hep3B/BCl-2 - Et

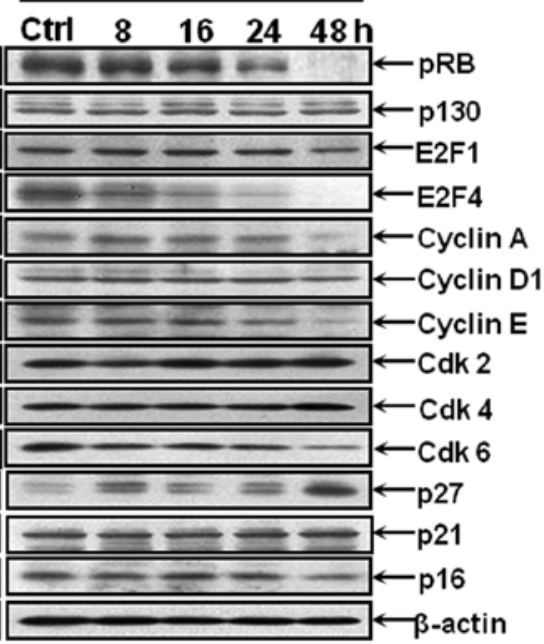

Hep3B/BCl-2 - St

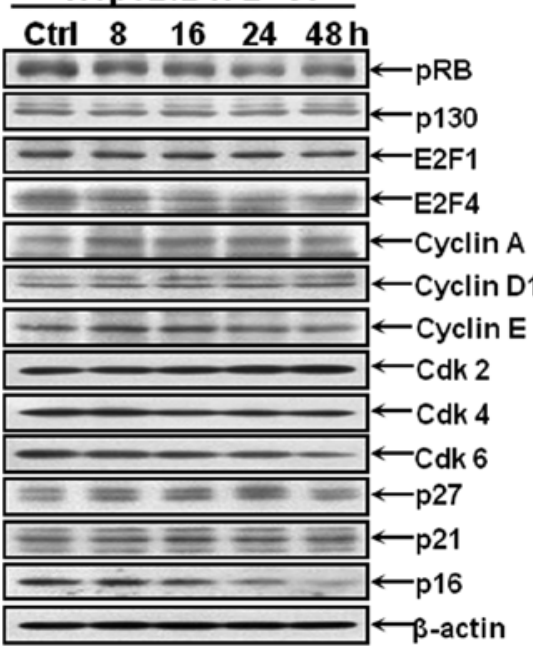

Figure 2. Etoposide induces $\mathrm{G}_{1} / \mathrm{S}$ phase arrest in $\mathrm{Hep} 3 \mathrm{~B} / \mathrm{vec}$ and $\mathrm{Hep} 3 \mathrm{~B} / \mathrm{Bcl}-2$ cells. (A) The kinetic analysis of the effect of $40 \mu \mathrm{g} / \mathrm{ml}$ etoposide or $300 \mathrm{nM}$ staurosporine on $\mathrm{Hep} 3 \mathrm{~B}$ cell cycle progression and the induction of subG $\mathrm{G}_{1}$ cells. Time-course analysis of cell-cycle distribution after etoposide treatment revealed an increase in the percentage of S-phase cells and also a sustained increase in the S-phase population, while producing a concomitant fall in the percentage of $\mathrm{G}_{0} / \mathrm{G}_{1}$ phase cells. Staurosporine treatment revealed an increase in the percentage of $\mathrm{G}_{2} / \mathrm{M}$-phase cells, while producing a concomitant fall in the percentage of $\mathrm{G}_{0} / \mathrm{G}_{1}$ phase cells. Representative DNA histograms are shown. (B) Western blot assay showing the expression levels of checkpoint proteins in the $\mathrm{G}_{1} / \mathrm{S}$ transition and cell cycle regulating factors at the $\mathrm{G}_{1} / \mathrm{S}$ boundary in Hep3B cells treated with etoposide but not with staurosproine. $\beta$-actin serves as a loading control. Figures are a representative result of four independent experiments. See Fig. 1 for other definitions.

(Fig. 2A). We next examined the expression levels of checkpoint proteins in the $\mathrm{G}_{1} / \mathrm{S}$ transition and cell cycle regulating factors at the $\mathrm{G}_{1} / \mathrm{S}$ boundary by western blot analysis. The total level of pRB expression decreased remarkably and changed from the hyperphosphorylated form to the hypophosphorylated form after etoposide treatment; however, staurosporine-treated cells remained unchanged. Moreover, the protein level of E2F-4 was completely inhibited after $48 \mathrm{~h}$ of exposure to etoposide; however, the level of E2F-1 was not. These results suggest that etoposide inhibits the release of E2F family proteins from $\mathrm{pRB}$. Furthermore, while the protein levels of cyclin A, cyclin E and Cdk6 were significantly inhibited by etoposide treatment in a time-dependent manner, the levels of cyclin D1, Cdk2 and Cdk4 remained unchanged in the etoposide-treated cells. These results suggest that the suppressive effects of etoposide at the $\mathrm{G}_{1} / \mathrm{S}$ phase in Hep3B cells are partly caused by downregulating the levels of cyclin A, cyclin E and Cdk6. Because Cdk activity is highly regulated by an association with Cdk inhibitors, such as p16, p21 and p27, we next examined the possible upregulation of these proteins in cells treated with etoposide or staurosporine. Noticeably, etoposide treatment resulted in a time-dependent increase in p27 protein, which was not undetectable in untreated control cells and staurosporine-treated cells. The expression levels of other Cdk inhibitors, such as p16 and p21, did not change after etoposide treatment (Fig. 2B). These data suggested that the etoposide-induced $\mathrm{G}_{1} / \mathrm{S}$ phase arrest in human hepatocarcinoma $\mathrm{Hep} 3 \mathrm{~B} / \mathrm{vec}$ and $\mathrm{Hep} 3 \mathrm{~B} / \mathrm{Bcl}-2$ cells requires increased p27 expression but not p16 and p21 expression. Taken together, etoposide, but not staurosporine, induces $\mathrm{G}_{1} / \mathrm{S}$ phase arrest in $\mathrm{Hep} 3 \mathrm{~B} / \mathrm{vec}$ and $\mathrm{Hep} 3 \mathrm{~B} / \mathrm{Bcl}-2$ cells.

Hep $3 B$ cells undergoing cell death after treatment with etoposide show apoptotic manifestations. To examine whether etoposide reduces the viability of $\mathrm{Hep} 3 \mathrm{~B} / \mathrm{vec}$ and $\mathrm{Hep} 3 \mathrm{~B} / \mathrm{Bcl}-2$ 
A

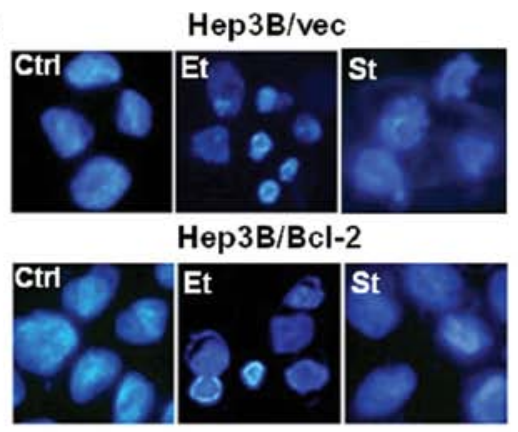

B
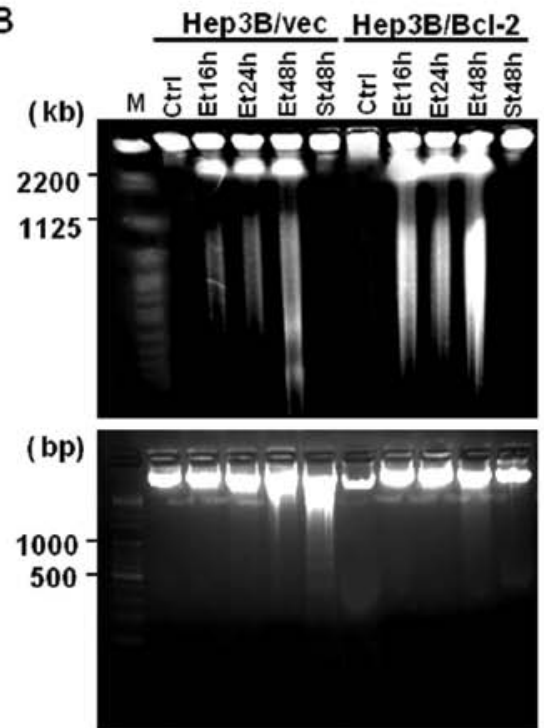

C

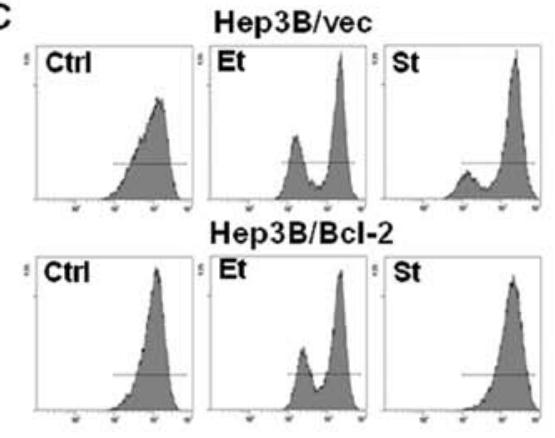

D

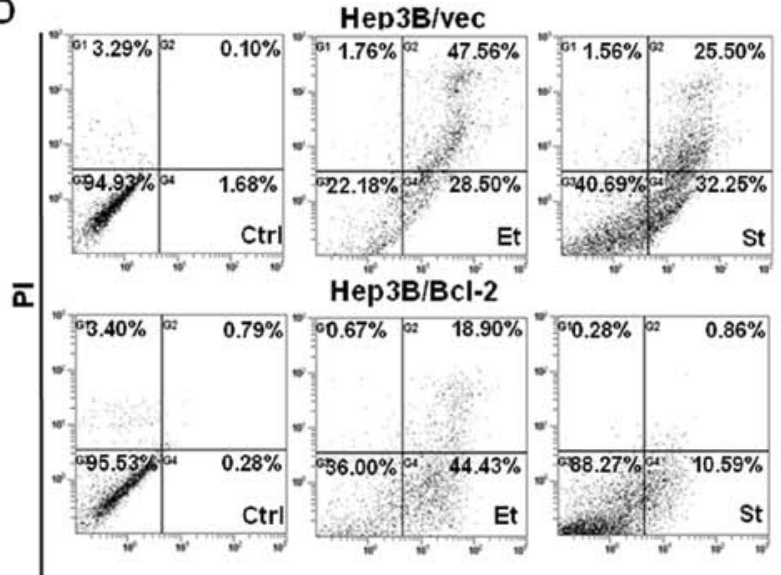

FITC

E Hep3B/vec $\mathrm{Hep} 3 \mathrm{~B} / \mathrm{Bcl}-2$ +S

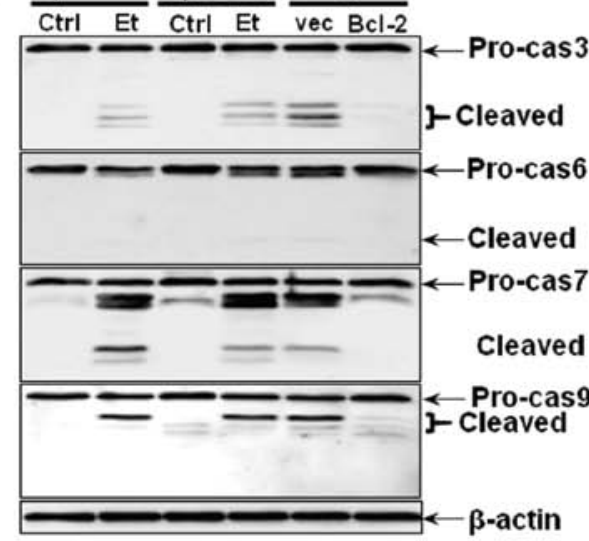

$\mathrm{F}$

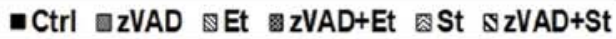

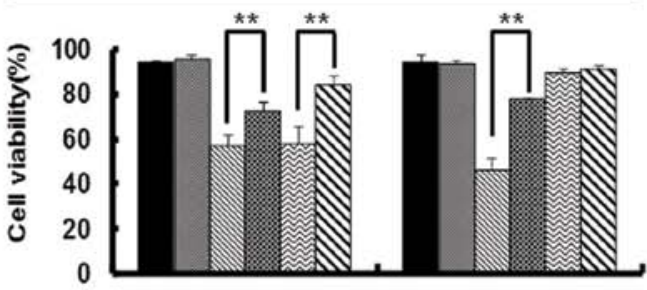

Hep3B/vec

Hep3B/Bcl-2

Figure 3. Hep3B cells undergoing cell death after treatment with etoposide or staurosporine show apoptotic phenotypes. (A) Hoechst staining showing nuclear condensation or fragmentation. (B) DNA electrophoresis and PFGE. While etoposide did not demonstrate ladder-like DNA fragments on agarose gel, disintegration of nuclear DNA into giant fragments of 1-2 Mbp and high molecular weight fragments of 200-800 kbp was recognized by PFGE. Staurosprine demonstrated a DNA ladder on an agarose gel. (C) Flow cytometry indicated a reduction in the mitochondrial membrane potential after treatment with etoposide or staurosporine. (D) Flow cytometry using Annexin V-FITC/PI double staining indicated the induction of apoptosis in Hep3B cells treated with etoposide or staurosporine. (E) Both etoposide and staurosporine produced the cleaved products procaspase-3, -6, -7 and -9. (F) A pan-caspase inhibitor zVAD-fmk significantly protected Hep3B cells against apoptosis in Hep3B cells induced by etoposide or staurosporine. ${ }^{* *} \mathrm{p}<0.01$. See Fig. 1 for other definitions.

cells by inducing apoptosis, various assays were performed. Hoechst staining showed nuclear condensation in Hep3B cells treated with etoposide or staurosporine (Fig. 3A). While etoposide did not demonstrate ladder-like DNA fragments on agarose gel, disintegration of nuclear DNA into giant fragments of 1-2 Mbp and high molecular weight fragments of 200-800 kbp were recognized by PFGE. Conversely, staurosporine demonstrated DNA ladder on an agarose gel (Fig. 3B). Flow cytometry indicated a reduction in the mitochondrial membrane potential (Fig. 3C). Flow cytometry using
Annexin V-FITC/PI double staining also demonstrated the induction of apoptosis in Hep3B cells treated with etoposide or staurosproine (Fig. 3D). Etoposide or staurosporine produced the cleaved products procaspase- $3,-6,-7$ and -9 in Hep3B cells (Fig. 3E). Etoposide treatment caused similar apoptotic phenotypes in Hep3B/Bcl-2 cells. However, Bcl-2 overexpression protected Hep3B cells against apoptosis induced by staurosporine (Fig. 3A-E). The pan-caspase inhibitor zVAD-fmk protected Hep3B cells against apoptosis induced by etoposide or staurosporine (Fig. 3F). Taken together, etoposide bypasses 
A
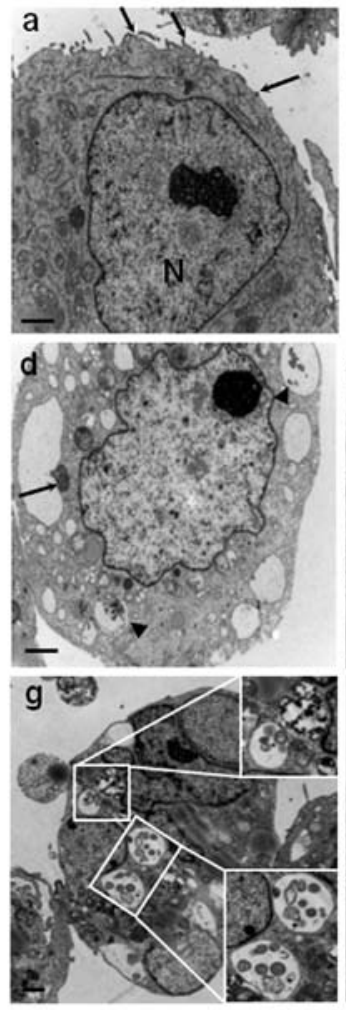

B

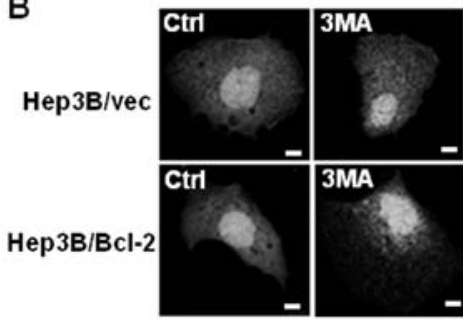

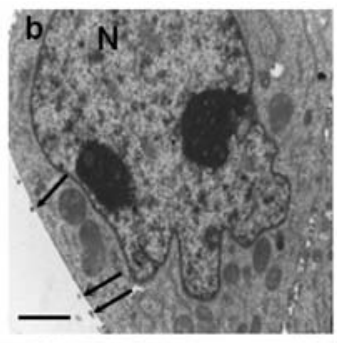
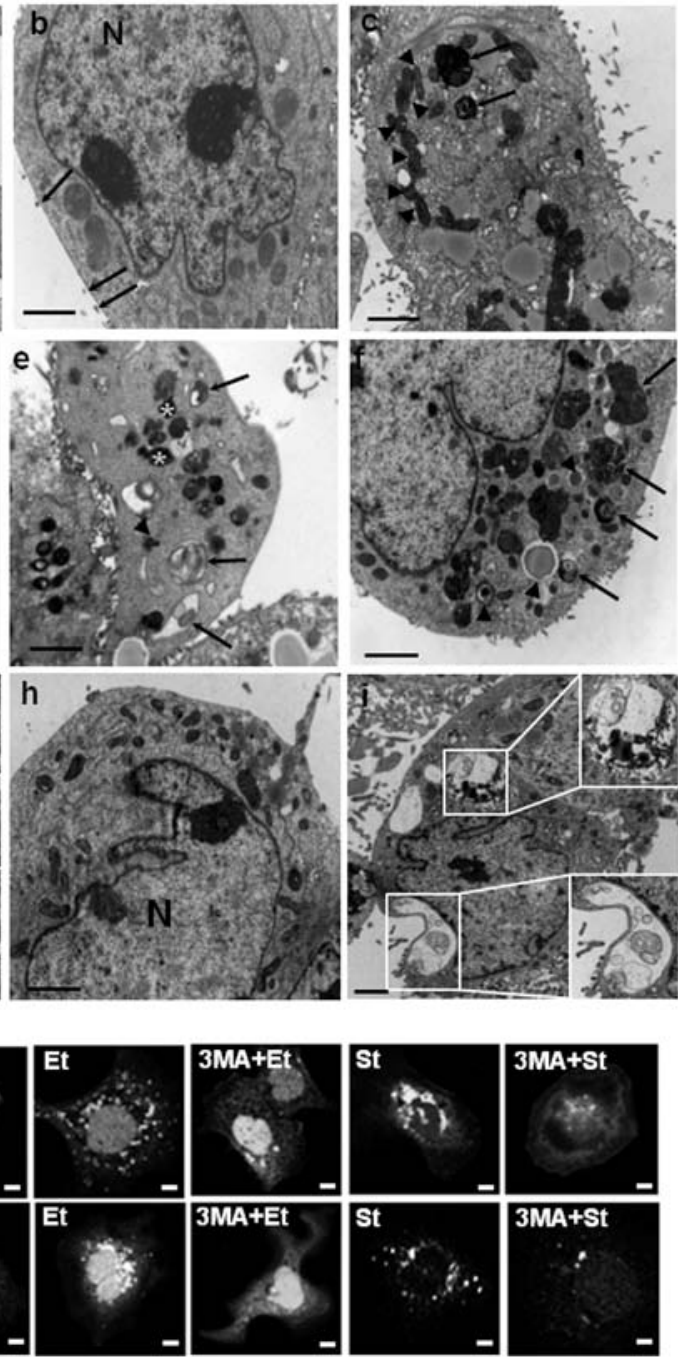

Figure 4. Hep3B cells treated with etoposide or staurosporine showed autophagic manifestations. (A) Transmission electron microscopy. Bars indicate $2 \mu \mathrm{m}$. (Panel a) A control Hep3B/vec cell. The Hep3B/vec cell shows a normal appearing nucleus (N) and a normal distribution of organelles with numerous microvilli (arrows). Mitochondria have a round to tubular shape with intact outer and inner membranes and cristae. The lumen of the ERs is not dilated. (Panel b) A control Bcl-2-overexpressing Hep3B cell. The Hep3B/Bcl-2 cell shows a normal appearing nucleus (N) and a normal distribution of organelles with numerous microvilli (arrows). Most mitochondria have a round shape with intact outer and inner membranes and cristae. The lumen of the ERs is not dilated. (Panel c) An etoposide-treated Hep3B/vec cell. Mitochondria were fragmented (arrowheads). Cellular organelles are merged with lysosomes, indicating the formation of autophagolysosomes (arrows). (Panel d) Another etoposide-treated Hep3B/vec cell. Numerous vesicles are observed. Cytoplasmic materials (arrow head) and mitochondria (arrow) were sequestered in these vesicles. (Panel e) A Bcl-2-overexpressing Hep3B cell treated with etoposide. Numerous vesicles are observed in the cytoplasm. Cup-shaped membrane structures were found, reflecting preautophagosomal structure phagopore formation (arrowhead). Autophagosomes contain mitochondria with membranous structures in different stages of degradation (arrows). Numerous autophagosomes were fused with lysosomes (asterisks). (Panel f) Another Bcl-2overexpressing Hep3B cell treated with etoposide. Autophagosome residual digested materials (arrowheads). Numerous autophagosomes were fused with lysosomes (arrows). (Panel g) A staurosporine-treated Hep3B/vec cell. The cell has numerous vacuoles, which includes cell organelles and cytoplasmic materials (insets). (Panel h) A Bcl-2-overexpression Hep3B cell treated with staurosporine. This cell shows a normal appearing nucleus (N) and a normal distribution of organelles with numerous microvilli. (Panel i) Another Bcl-2 overexpression Hep3B cell treated with staurosporine. The cell has numerous vacuoles, which include cell organelles, membranous structures and cytoplasmic materials (insets). (B) Confocal microscopy demonstrated that etoposide or staurosporine treatment induced LC 3 puncta in Hep3B/Bcl-2 cells and Hep3B/vec cells transfected with GFP-LC3. Additionally, 3MA suppressed the appearance of a punctuate LC3 pattern and prevented the formation of LC3 puncta. Bars, $10 \mathrm{~mm}$. See Fig. 1 for other definitions.

the chemoresistance conferred by Bcl-2 in Hep3B cells via the induction of apoptosis.

Hep3B cells treated with etoposide or staurosporine show autophagic phenotypes. We next observed the fine structure of Hep3B/vec and Hep3B/Bcl-2 cells treated with etoposide. The control Hep3B/vec cell has a normal appearing nucleus and a normal distribution of organelles with numerous microvilli. Mitochondria have a round to tubular shape with intact outer and inner membranes and cristae. The lumen of the ERs is not dilated. The control Bcl-2 overexpressing Hep3B cell also shows a normal appearance of the nucleus and a normal distribution of organelles with numerous microvilli. Most mitochondria have a round shape with intact outer and inner membranes and cristae. The lumen of the ERs is not dilated (Fig. 4Aa and 4Ab). The etoposide-treated Hep3B/vec cells have mitochondria that are fragmented. Cellular organelles are merged with lysosomes, indicating the formation of an autophagolysosome. Numerous vesicles with a double membrane are observed in the cytoplasm. The Bcl-2 overexpressing Hep3B cells treated with etoposide also 
A

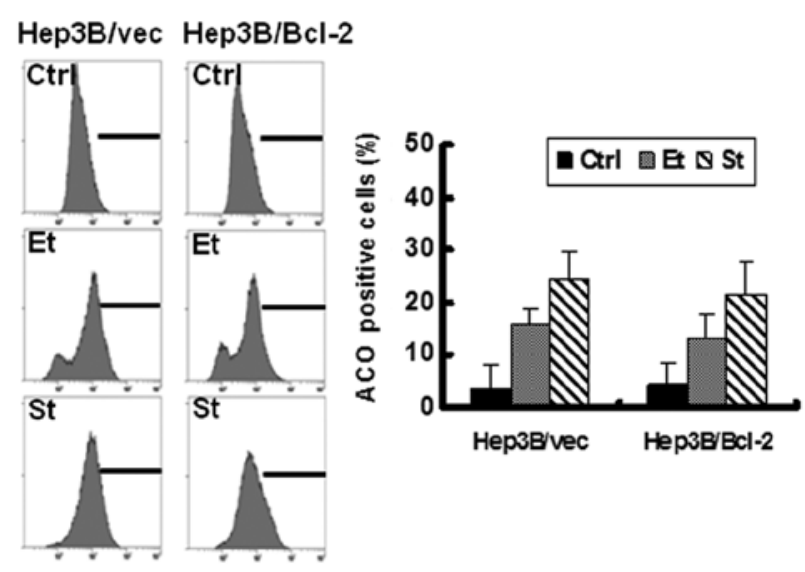

B

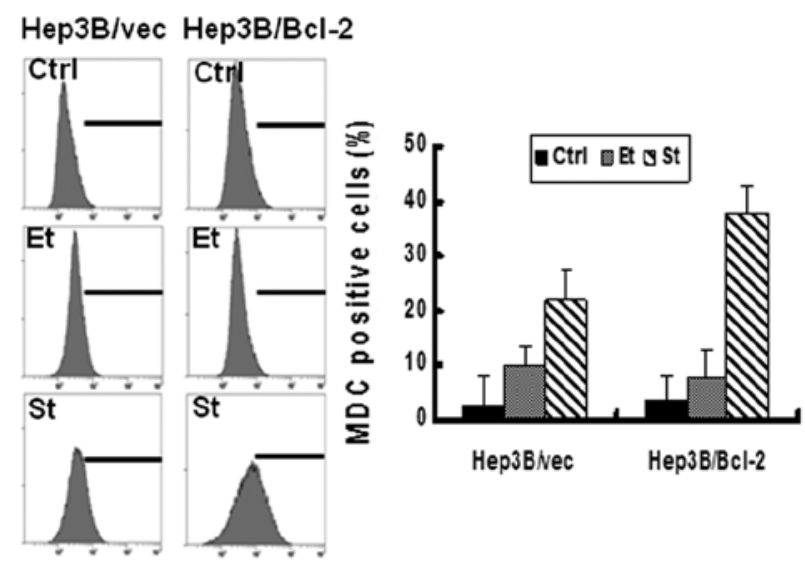

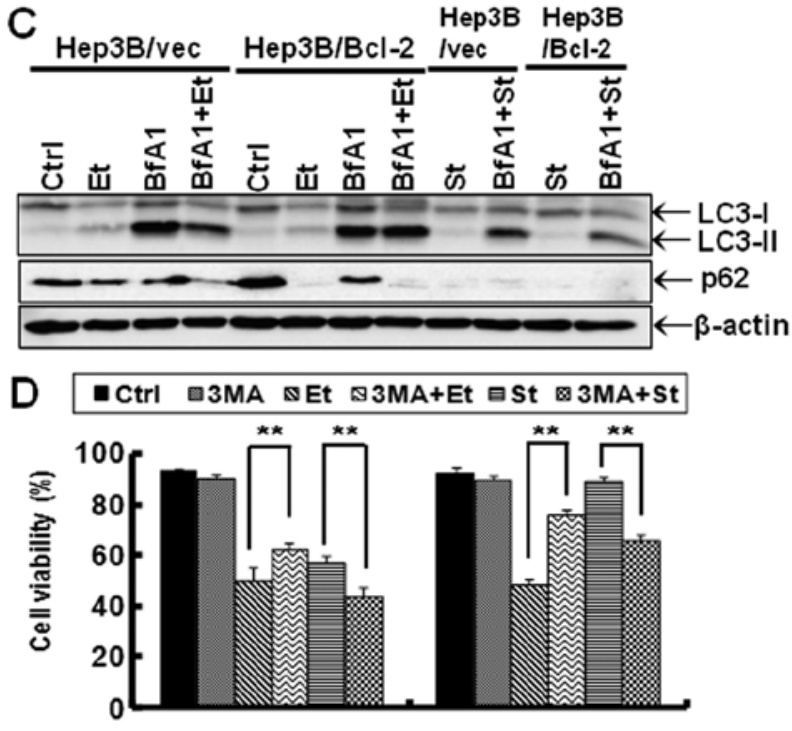

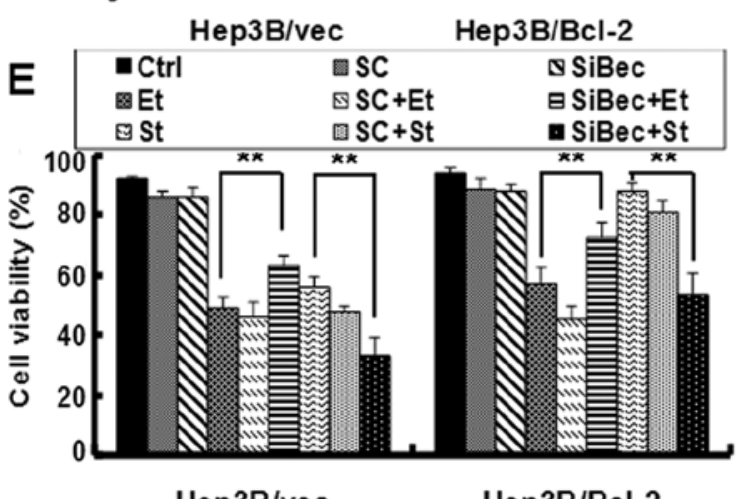

Hep3B/vec

Hep3B/Bcl-2

Figure 5. Autophagy in Hep3B cells induced by etoposide and staurosporine is cell death-inducing and cyto-protective in Hep3B cells, respectively. Cells with positive staining were monitored using flow cytometry $48 \mathrm{~h}$ after treatment with etoposide or staurosporine. (A) Flow cytometric histograms showing the intensity of red fluorescence in acridine orange-stained cells (left panel). Flow cytometric analysis indicates the percent of acridine-orange positive cells, which is represented as the mean $\pm \mathrm{SD}$ (right panel). The percentage of acridine orange-positive cells is larger in cells treated with etoposide or staurosporine compared to untreated control cells. The percentage of acridine orange-positive cells is larger in cells treated with etoposide than in cells treated with staurosporine. (B) Flow cytometric histograms showing increased MDC recruitment to autophagosomes in Hep3B/vec and Hep3B/Bcl-2 cells treated with etoposide or staurosporine (left panel). Flow cytometric analysis indicates the percent of MDC positive cells, which is represented as the mean \pm SD (right panel). The percentage of MDC-positive cells is larger in cells treated with etoposide or staurosporine compared to untreated control cells. The percentage of MDC-positive cells is larger in cells treated with etoposide compared to cells treated with staurosporine. (C) Autophagy flux assay based on the turnover of LC3-II by western blot analysis in the presence and absence lysosomal degradation. The cells were pretreated with bafilomycin A1 for $3 \mathrm{~h}$ and were further exposed to etoposide or staurosporine for $48 \mathrm{~h}$. BfA1, bafilomycin A1. Western blot analysis shows that an increase in LC3-II in cells treated with etoposide was markedly enhanced by bafilomycin A1 treatment. Although LC3-II is not observed in Hep3B cells treated with staurosporine alone, bafilomycin A1 treatment evidently increased LC3-II in staurosporine-treated Hep3B cells. (D) Viability assay showing the effect of the inhibition of autophagy by $3 \mathrm{MA}$, which also significantly prevents the reduction in viability by etoposide, in Hep3B/ vec and $\mathrm{Hep} 3 \mathrm{~B} / \mathrm{Bcl}-2$ cells. ${ }^{* *} \mathrm{p}<0.01$. Conversely, $3 \mathrm{MA}$ significantly augmented the reduction in viability by staurosporine in Hep3B/vec and Hep3B/Bcl-2 cells. ${ }^{* *} \mathrm{p}<0.01$. (E) Viability assay showing the effect of the inhibition of autophagy by siRNA against Beclin 1. Additionally, siRNA against Beclin-1 significantly prevents the reduction in viability by etoposide in Hep3B/vec and Hep3B/Bcl-2 cells. ${ }^{* *} \mathrm{p}<0.01$. Conversely, siRNA against Beclin-1 significantly augments the reduction in viability by staurosporine in Hep3B/vec and Hep3B/Bcl-2 cells. * p $<0.01$. SC, scrambled siRNA; SiBec, siRNA Beclin-1. See Fig. 1 for other definitions.

had numerous vesicles with a double membrane in the cytoplasm. Cup-shaped membrane structures were found, reflecting preautophagosomal structure phagopore formation. Autophagosomes contained mitochondria and membranous structures in different stages of degradation. Numerous autophagosomes were fused with lysosomes. Autophagosomes contained mitochondria and lamellar structures with residual digested materials (Fig. 4Ac-Af). Staurosporine-treated Hep3B cell also showed autophagic phenotypes (Fig. 4Ag). Bcl-2 overexpressing Hep3B cells showed the normal appearance (Fig. 4Ah) or autophagic phenotypes (Fig. 4Ai). Confocal microscopy demonstrated that etoposide or staurosporine induced LC3 puncta in Hep3B cells transfected with GFP-LC3 (Fig. 4B). These findings indicate that etoposide or staurosporine treatment induces autophagy in Hep3B and Hep3B/Bcl-2 cells.

Autophagy in Hep3B cells induced by etoposide and staurosproine is cell death-inducing and cyto-protective, respectively. We next examined autophagic flux. Flow cytometry revealed increased acridine orange intensity or MDC recruitment to autophagosomes in $\mathrm{Hep} 3 \mathrm{~B} / \mathrm{vec}$ and $\mathrm{Hep} 3 \mathrm{~B} / \mathrm{Bcl}-2$ cells treated with etoposide or staurosporine. These data indicate that both etoposide and staurosporine increase the percent of cells with acidic vesicular organelles. Importantly, the percent of both 

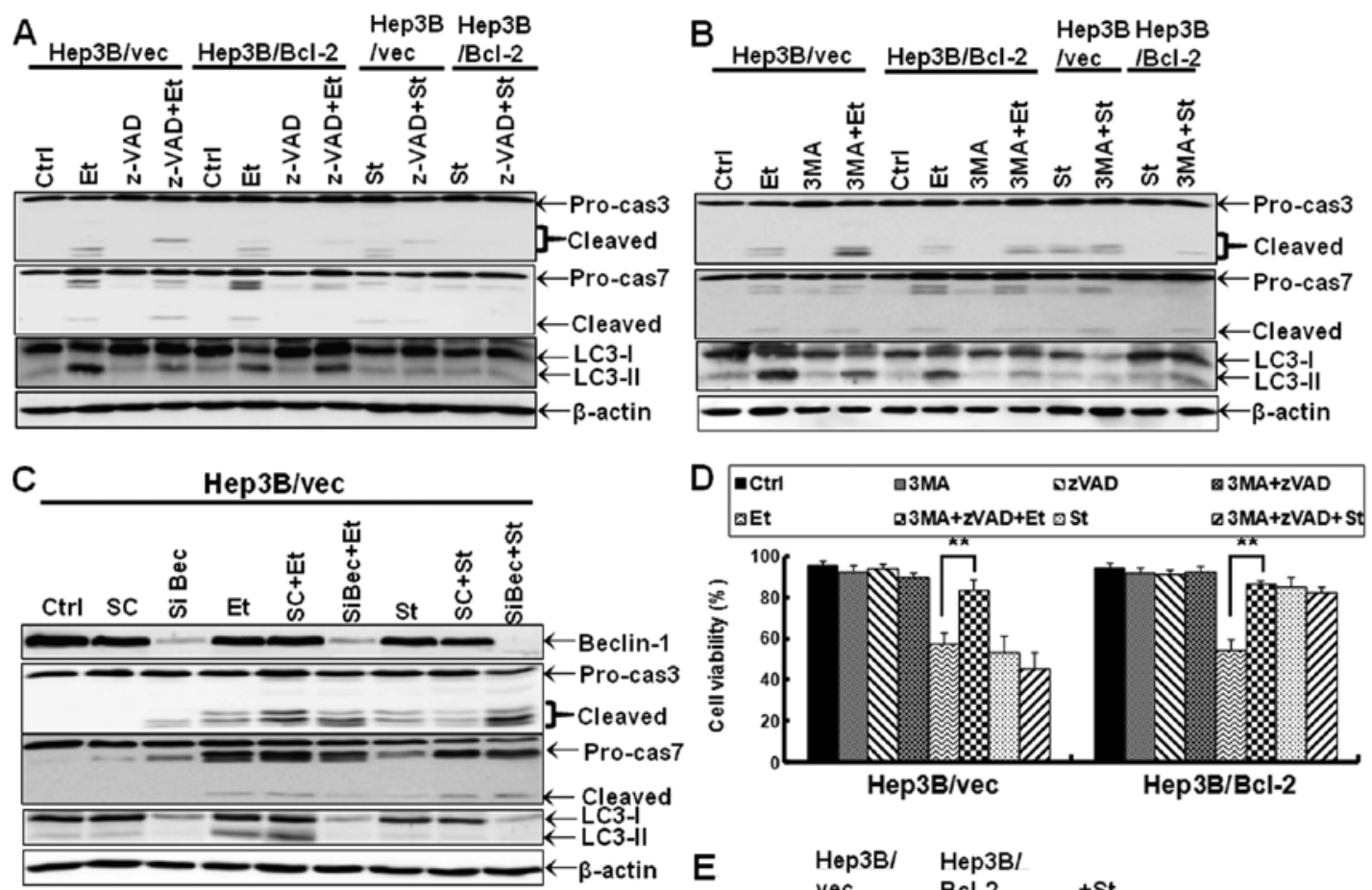

Hep3B/Bcl-2
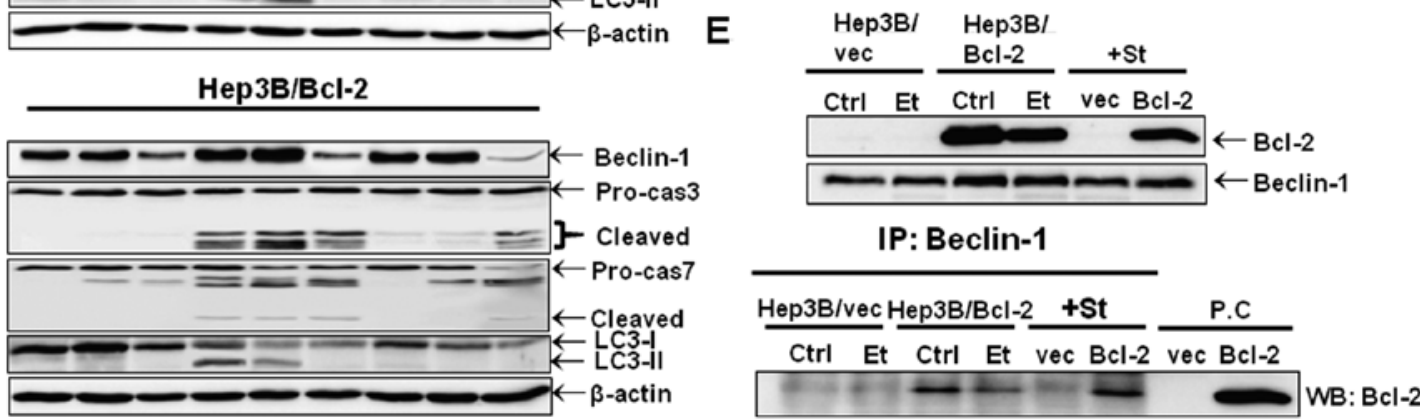

Figure 6. Apoptosis and autophagic cell death occurs independently in etoposide-treated Hep3B cells. The cells were pretreated with 3MA (1 mM) and zVAD-fmk $(100 \mu \mathrm{M})$ for $3 \mathrm{~h}$, respectively, and were further exposed to etoposide or staurosporine for $48 \mathrm{~h}$. (A) A pan-caspase inhibitor zVAD-fmk did not prevent an increase in LC3-II, although it efficiently prevented the activation of effect of caspase-3 and -7. (B) 3MA did not prevent the activation of caspase-3 and -7, although it efficiently prevented an increase in LC3-II. (C) Beclin-1 siRNA did not prevent the activation of caspase-3 and -7, although it efficiently prevented an increase in LC3-II. (D) The viability assay showed that co-treatment with 3MA and zVAD-fmk almost completely abolished the reduction in viability by etoposide. ${ }^{* *}$ p $<0.01$ (E) Decreased interaction between Bcl-2 and Beclin-1 by etoposide. Vec, Hep3B/vec cells; Bcl-2, Hep3B/Bcl-2 cells. Western blot assay shows that both etoposide and staurosporine slightly downregulate the expression of Bcl-2 protein in $\mathrm{Hep} 3 \mathrm{~B} / \mathrm{Bcl}-2$ cells (upper panel). Co-immunoprecipitation shows that etoposide but not staurosporine reduces the interaction between Bcl-2 and Beclin-1 in Hep3B/Bcl-2 cells (lower panel). PC, positive control. See Figs. 1 and 5 for other definitions .

acridine orange- and MDC-positive cells was substantially higher in staurosporine-treated cells than in etoposide-treated cells (Fig. 5A and B). We further conducted an autophagy flux assay based on the turnover of LC3-II by western blot analysis in the presence and absence lysosomal degradation. To prevent lysosomal degradation, bafilomycin A1 was used. A western blot assay showed that an increase in LC3-II levels in cells treated with etoposide was markedly enhanced by bafilomycin A1 treatment (Fig. 5C). Although LC3-II is not observed in Hep3B cells treated with staurosporine alone, bafilomycin A1 treatment evidently increased LC3-II level in staurosporine-treated Hep3B cells. These data indicate that autophagic flux, which refers to the complete process of autophagy, is more active in staurosporine-treated cells compared to etoposide-treated cells. We next examined the effect of the inhibition of autophagy on the reduction of cell viability by etoposide or staurosporine. We observed that the inhibition of autophagy by 3MA or siRNA against Beclin-1 prevented the reduction in viability by etoposide in $\mathrm{Hep} 3 \mathrm{~B} / \mathrm{vec}$ and $\mathrm{Hep} 3 \mathrm{~B} / \mathrm{Bcl}-2$ cells. Conversely, the inhibition of autophagy by 3MA or siRNA against Beclin-1 augmented the reduction in viability by staurosporine in Hep3B/vec and Hep3B/Bcl-2 cells (Fig. 5D and E). These findings indicate that autophagy in Hep3B cells induced by etoposide and staurosproine is cell death-inducing and cyto-protective in Hep3B cells, respectively.

Apoptotic and autophagic cell death occur independently in etoposide-treated Hep3B cells. Because our data support that etoposide induces a mixed type of programmed cell death, we further examined whether necroptosis, another type of programmed cell death, plays a role in the cell death of etoposide-treated Hep3B cells. However, necrostatin-1 did not alter the amount of the etoposide-mediated cell death (negative data not shown). These data suggest that etoposide induces a mixed type of programmed cell death via apoptosis and autophagic cell death and overcomes the resistance conferred by Bcl-2 in Hep3B hepatoma cells. We next asked whether autophagic cell death induced by etoposide interplays with apoptosis in this type of 
cell death. We observed that a pan-caspase inhibitor zVAD-fmk did not prevent the increase in LC3-II, although it efficiently prevented the activation of caspase-3 and -7 (Fig. 6A). We further observed that $3 \mathrm{MA}$ did not prevent the activation of caspase- 3 or caspase-7, although it efficiently prevented the increase in LC3-II (Fig. 6B). Beclin-1 siRNA also showed a similar effect with 3MA (Fig. 6C). The viability assay showed that co-treatment with 3MA and zVAD-fmk almost completely abolished the reduction in viability by etoposide (Fig. 6D). Although we did not completely exclude the possibility that autophagic cell death leads to apoptosis or vice versa in Hep3B cells treated with etoposide, our data suggest that autophagy and apoptosis may contribute to cell death independently, bypassing the resistance conferred by Bcl-2. Conversely, co-treatment with 3MA and zVAD-fmk did not prevent the reduction in viability induced by staurosporine (Fig. 6D), although zVAD-fmk and 3MA or Beclin-1 siRNA protected Hep3B cells against apoptotic and autophagic phenotypes in Hep3B cells treated with staurosporine, respectively. In concert with the data showing that zVAD-fmk almost completely abolished the reduction in viability by staurosporine (Fig. 3F), these data indicate that autophagy does not contribute to cell death in Hep3B cells treated with staurosporine.

Etoposide decreases the Bcl-2 to Beclin-1 interaction. To this end, we examined whether etoposide has the ability to dissociate the interaction between Bcl-2 and Beclin-1. According to western blot data, both etoposide and staurosporine slightly downregulated the expression of Bcl-2 protein in $\mathrm{Hep} 3 \mathrm{~B} / \mathrm{Bcl}-2$ cells. Importantly, etoposide but not staurosporine dissociated the interaction between Bcl-2 and Beclin-1 (Fig. 6E).

\section{Discussion}

Although surgery is the most effective treatment for hepatocellular carcinoma (HCC), the numbers of patients with HCC who are eligible for surgical intervention are limited. Thus, numerous approaches have been conducted to search for other options, such as efficient chemotherapeutic agents. However, HCC is weakly chemosensitive (14).

One of the most important problems that hamper the efficiency of cancer chemotherapeutic drugs, such as cisplatin and etoposide, is chemoresistance $(15,16)$. Accumulated data strongly suggest a causal relationship between defects in apoptosis and drug resistance (17). The expression of genes that regulate apoptotic cell death plays an important role in determining the sensitivity of tumor cells to chemotherapy. Although most of the anticancer drugs, regardless of their targets and mechanisms, ultimately induce apoptosis, cancer cells are genetically predisposed to apoptotic resistance, blocking the action of anticancer drugs. For example, the efficacy of anthracycline antibiotics can be significantly reduced after cancers develop apoptotic resistance (18). Similarly, the efficacy of other anticancer agents, such as vinca alkaloids, taxanes, epipodophylotoxins, and imatinib, is reduced with the cancer resistance to apoptosis (19).

Autophagy has been used to describe the catabolic pathways of the degradation of intracellular macromolecules. Autophagy begins with the sequestration of intracellular cargo, such as protein aggregates, organelles and ribosomes, in a membrane vacuole called an autophagosome. Next, the loaded autophagosome fuses with lysosomes, where the cellular materials are degraded by lysosomal acid proteases, and lysosomal permeases and transporters export amino acids and other by-products of degradation back out to the cytoplasm, where they can be re-used for building macromolecules and for metabolism (20). In theory, autophagy may help promote cell survival either by promoting energy efficiency through ATP generation or by mediating damage control by removing non-functional proteins and organelles (21). Numerous studies have demonstrated that autophagy protects cells by preventing them from undergoing apoptosis. Autophagy sequesters damaged mitochondria, preventing cytochrome $c$ from being able to form a functional apoptosome, and protects cells from the caspase-independent death that occurs after mitochondrial outer membrane permeabilization (MOMP) $(22,23)$. Thus, autophagy may contribute to chemoresistance by preventing apoptosis.

Paradoxically, autophagy may also represent a form of nonapoptotic cell death. Numerous recent studies have shown that increased autophagic activity is associated with cell death $(24,25)$. Although it is unclear whether autophagy directly contributes to cell death or is a failed effort to preserve cell viability, autophagy appears to promote cell death through the excessive self-digestion and degradation of essential cellular constituents. Unlike apoptosis, autophagic cell death is usually considered caspase-independent (25). Furthermore, autophagic cell death is known to occur in cells with profound defects in the apoptotic machinery (26). However, autophagic cell death undergoes cross-talk with apoptosis via classical apoptotic mediators and involves the caspase-dependent mechanism in some circumstances (27). In this context, autophagic cell death defects may also contribute to chemoresistance. Thus, the induction of autophagic cell death could be a strategy in circumventing cancer drug resistance.

Etoposide acts as a topoisomerase II inhibitor. Topoisomerase II modulates DNA topology during synthesis by passing an intact helix through a transient double stranded break before closing up for further extension, thereby regulating over- and under-winding of the backbone and resolving knots and tangles (28). Etoposide induces covalent protein DNA complex formation, impairing this mode of progression (29). Although topoisomerase inhibitor-induced DNA damage is known to induce apoptosis, the signaling pathway has not been fully defined (18). The mechanisms involved in the induction of apoptosis by topoisomerase inhibitors are believed to be largely mediated by the mitochondrial apoptotic pathway (30). Because Bcl-2 plays a central role in regulating changes in mitochondrial outer membrane permeability (3), Bcl-2 inhibits the mitochondria-dependent apoptosis induced by etoposide. Because increased expression of Bcl-2 has been associated with poor response to chemotherapy in various malignancies, overexpression of Bcl-2 justly appears to inhibit or attenuate the pathway to apoptosis (31).

However, previous studies have demonstrated that chemotherapeutic drugs can bypass Bcl-2-mediated protection against apoptosis in Bcl-2-overexpressing cells (32). Although the molecular mechanism of cell death in Bcl-2-overexpressing cells remains unclear, the involvement of lipid peroxidation, the modulation of p53 target genes, such as Puma and Noxa, and the formation of PML (promyelocytic leukemia) nuclear bodies have been suggested to underlie the induction of apoptosis in Bcl-2-overexpressing cells. 
Arguably, the most intriguing finding of our study is that etoposide bypasses the resistance by inducing a mixed type of programmed cell death in Hep3B hepatoma cells. On the basis of previous studies showing that blocked apoptosis contributes to cancer drug resistance, most pharmacological approaches have been aimed at restoring the efficacy of chemotherapeutics by activating apoptosis. However, cancer drug resistance is complex in nature, and many different types of cell death appear to contribute to cancer drug resistance. Previous studies have shown that the induction of necroptosis circumvents apoptotic resistance (33). Therefore, simultaneous activation of multiple death pathways seems to be an effective strategy to bypass cancer cell resistance. To date, few chemicals have been demonstrated to induce multiple types of programmed cell death. The concomitant occurrence of autophagy and necroptosis (34) or apoptosis and autophagic cell death has been reported (35). According to their data, two PCDs independently contribute to cell death execution or the one PCD is the consequence of the other PCD. Our data suggest that etoposide induces PCD I and PCD II concomitantly, both of which contribute to the cytotoxic effects in Hep3B / Bcl-2 and Hep3B cells.

Another interesting finding is that the concomitant occurrence of apoptosis and autophagy after etoposide treatment is mediated with cell cycle arrest in the $\mathrm{G}_{1} / \mathrm{S}$ phase. The progression of eukaryotic cells through the cell cycle is orchestrated by the sequential activation and inactivation of the Cdks, which is associated with their respective cyclin subunits. $G_{1}$ progression and $G_{1} / S$ transition are regulated by $\mathrm{Cdk} 4 / \mathrm{Cdk} 6$, which assemble with $D$-type cyclins during the mid- $\mathrm{G}_{1}$ phase and with $\mathrm{Cdk} 2$, which later combines with cyclin E. Although Cdk2 controls the S-phase when it is associated with cyclin A, the $\mathrm{G}_{2} / \mathrm{M}$ transition is regulated by $\mathrm{Cdk} 2$ in combination with cyclins A and B (36). Moreover, the relative balance between the cellular concentrations of $\mathrm{Cdk}$ inhibitors also regulates cell cycle progression. Cdk inhibitors are divided into two families according to substrate specificity. In mammalian cells, these are the CIP/KIP family, which consists of p21, p27 and p57, and the INK4a family, including p15, p16 and p18 (37). Cdk inhibitors mediate cell cycle arrest in response to several antiproliferative signals. The activity of Cdks is also negatively regulated by binding to $\mathrm{Cdk}$ inhibitors in response to a variety of antiproliferative signals and thus modulates retinoblastoma protein (pRB) phosphorylation events, which are essential for various cell cycle transitions (38). These observations suggest new approaches that could alter uncontrolled human cancer cell growth by modulating cell cycle regulators causing cell cycle arrest and could be useful in prevention and/or intervention in human cancer (39). In line with several previous studies reporting that etoposide could induce S-phase arrest (40), etoposide induced S-phase arrest in Hep3B cells. Numerous previous studies have reported that cell cycle arrest is associated with the induction of apoptosis. Furthermore, recent studies have suggested that cell cycle arrest is associated with autophagy. Among those studies, only a few studies have shown that autophagy is associated with S-phase arrest (41). According to recent studies, the functional networks of cell cycle, apoptosis and autophagy appear to be intermingled. Cell cycle machineries are involved in the progress of apoptosis and autophagy. In light of our results, etoposide targets many proteins in Hep3B cells, leading to cell cycle arrest, apoptosis and autophagic cell death, which determine cell fate; however, the entire molecular mechanism is not fully understood.

Because autophagy and apoptosis can be triggered by overlapping signaling mechanisms, and because Bcl-2 plays important roles in inhibiting not only apoptosis but also autophagy (42), Bcl-2 is an important potential therapeutic target for overcoming cancer cell resistance by a simultaneous activation of apoptosis and autophagy. However, to date, only a few chemicals have been reported to simultaneously activate apoptosis and autophagic cell death. In contrast to a previous study showing Bcl-2-mediated etoposide resistance in 697 leukemia cells, we observed that etoposide concomitantly activates apoptosis and autophagic cell death in Bcl-2-overexpressing Hep3B cells.

This study revealed that etoposide dissociates the interaction between Bcl-2 and Beclin-1 in Hep3B cells, efficiently inducing autophagic cell death in Hep3B cells. Bcl-2 helps maintain mitochondrial integrity, protects cells from apoptosis, and when bound to Beclin-1, can inhibit autophagy as well (43). Autophagy is initially induced to prolong cell survival, but when taken to extremes, it causes cell death. Bcl-2 suppresses autophagy by binding to the protein Beclin-1. Thus, Bcl-2 can help cells evade autophagic cell death. We also observed the induction of autophagy in Hep3B cells treated with staurosporine, which is a strong inducer of apoptosis in many different cell types. However, autophagy induced by staurosproine in Hep3B cells is associated with cell survival but not with autophagic cell death. Importantly, staurosporine neither dissociated the interaction between Bcl-2 and Beclin-1 nor bypassed the resistance conferred by Bcl-2 in Hep3B cells. These data suggest that bypassing resistance with etoposide in Hep3B cells can be associated with the efficacy of etoposide in dissociating the interaction between Bcl-2 and Beclin-1.

In conclusion, etoposide bypasses the resistance by inducing a mixed type of programmed cell death in Hep3B hepatoma cells. Because multiple mechanisms may be involved in etoposide-cell death in Bcl-2-overexpressing cancer cells and may vary between different cell types, further studies are required.

\section{Acknowledgements}

This study was supported by the National Research Foundation of Korea grant funded by the Korean government (2010-0001942).

\section{References}

1. Kroemer G, Galluzzi L, Vandenabeele P, Abrams J, Alnemri ES, Baehrecke EH, Blagosklonny MV, El-Deiry WS, Golstein P, Green DR, Hengartner M, Knight RA, Kumar S, Lipton SA, Malorni W, Nunez G, Peter ME, Tschopp J, Yuan J, Piacentini M, Zhivotovsky B and Melino G: Classification of cell death: recommendations of the Nomenclature Committee on Cell Death. Cell Death Differ 16: 3-11, 2009.

2. Oltvai ZN, Milliman CL and Korsmeyer SJ: Bcl-2 heterodimerizes in vivo with a conserved homolog, Bax, that accelerates programmed cell death. Cell 74: 609-619, 1993.

3. Adams JM and Cory S: The Bcl-2 protein family: arbiters of cell survival. Science 281: 1322-1326, 1998.

4. Murphy KM, Streips UN and Lock RB: Bcl-2 inhibits a Fas-induced conformational change in the Bax $\mathrm{N}$ terminus and Bax mitochondrial translocation. J Biol Chem 27: 17225-17228, 2000 . 
5. Foyouzi-Youssefi R, Arnaudeau S, Borner C, Kelley WL, Tschopp J, Lew DP, Demaurex N and Krause KH: Bcl-2 decreases the free $\mathrm{Ca}^{2+}$ concentration within the endoplasmic reticulum. Proc Natl Acad Sci USA 97: 5723-5728, 2000.

6. Saeki K, You A, Okuma E., Yazaki Y, Susin SA, Demaurex N and Krause $\mathrm{KH}$ : Bcl-2 down-regulation causes autophagy in a caspase-independent manner in human leukemic HL60 cells. Cell Death Differ 7: 1263-1269, 2000.

7. Pattingre S, Tassa A, Qu X, Garuti R, Liang XH, Mizushima N, Packer M, Schneider MD and Levine B: Bcl-2 antiapoptotic proteins inhibit Beclin-1-dependent autophagy. Cell 122: 927-939, 2005.

8. Liang XH, Kleeman LK, Jiang HH, Gordon G, Goldman JE, Berry G, Herman B and Levine B: Protection against fatal Sindbis virus encephalitis by Beclin, a novel Bcl-2-interacting protein. J Virol 72: 8586-8596, 1998.

9. Reed JC, Miyashita T, Takayama S, Wang HG, Sato T, Krajewski S, Aime-Sempe C, Bodrug S, Kitada S and Hanada M: BCL-2 family proteins: regulators of cell death involved in the pathogenesis of cancer and resistance to therapy. J Cell Biochem 60: 23-32, 1996.

10. Letai AG: Diagnosing and exploiting cancer's addiction to blocks in apoptosis. Nat Rev Cancer 8: 121-132, 2008.

11. Real PJ, Cao Y, Wang R, Nikolovska-Coleska Z, Sanz-Ortiz J, Wang S and Fernandez-Luna JL: Breast cancer cells can evade apoptosis-mediated selective killing by a novel small molecule inhibitor of Bcl-2. Cancer Res 64: 7947-7953, 2004.

12. Chen Ay and Liu LF: DNA topoisomerases: Essential enzymes and lethal targets. Annu Rev Pharmacol Toxicol 3: 191-218, 1994.

13. Dubrez L, Goldwasser F, Genne P, Pommier Y and Solary E: The role of cell cycle regulation and apoptosis triggering in determining the sensitivity of leukemic cells to topoisomerase I and II inhibitors. Leukemia 9: 1013-1024, 1995.

14. Cohn AL, Myers JW, Mamus S, Deur C, Nicol S, Hood K, Khan MM, Ilegbodu D and Asmar L: A phase II study of pemetrexed in patients with advanced hepatocellular carcinoma. Invest New Drugs 26: 381-386, 2008

15. Lee JO, Lee KW, Oh DY, Kim JH, Im SA, Kim TY and Bang YJ: Combination chemotherapy with capecitabine and cisplatin for patients with metastatic hepatocellular carcinoma. Ann Oncol 20: 1402-1407, 2009.

16. Yuan JN, Chao Y, Lee WP, Li CP, Lee RC, Chang FY, Yen SH, Lee SD and Whang-Peng J: Chemotherapy with etoposide, doxorubicin, cisplatin, 5-fluorouracil, and leucovorin for patients with advanced hepatocellular carcinoma. Med Oncol 25: 201-206, 2008.

17. Johnstone RW, Ruefli AA and Lowe SW: Apoptosis: a link between cancer genetics and chemotherapy. Cell 108: 153-164, 2002.

18. Gewirtz DA: A critical evaluation of the mechanisms of action proposed for the antitumor effects of the anthracycline antibiotics Adriamycin and daunorubicin. Biochem Pharmacol 57: 727-741, 1999

19. Jordan MA and Wilson L: Microtubules as a target for anticancer drugs. Nat Rev Cancer 4: 253-265, 2004

20. Mizushima N: Autophagy: process and function. Genes Dev 21: 2861-2873, 2007

21. Glick D, Barth S and Macleod KF: Autophagy: cellular and molecular mechanisms. J Pathol 221: 3-12, 2010.

22. Ravikumar B, Berger Z, Vacher C, O'Kane CJ and Rubinsztein DC: Rapamycin pre-treatment protects against apoptosis. Hum Mol Genet 15: 1209-1216, 2006.

23. Colell A, RicciJE, TaitS, Milasta S, Maurer U,Bouchier-Hayes L, Fitzgerald P, Guio-Carrion A, Waterhouse NJ, Li CW, Mari B Barbry P, Newmeyer DD, Beere HM and Green DR: GAPDH and autophagy preserve survival after apoptotic cytochrome c release in the absence of caspase activation. Cell 129: 983-997, 2007.

24. Tsujimoto Y and Shimizu S: Another way to die: autophagic programmed cell death. Cell Death Differ 12 (Suppl 2): $1528-1534,2005$.
25. Gozuacik D and Kimchi A: Autophagy as a cell death and tumor suppressor mechanism. Oncogene 23: 2891-2906, 2004.

26. Shimizu S, Kanaseki T, Mizushima N, Mizuta T, ArakawaKobayashi S, Thompson CB and Tsujimoto Y: Role of Bcl-2 family proteins in a non-apoptotic programmed cell death dependent on autophagy genes. Nat Cell Biol 6: 1221-1228, 2004.

27. Lee SW, Song YS, Lee SY, Yoon YG, Lee SH, Park BS, Yun I, Choi H, Kim K, Chung WT and Yoo YH: Downregulation of protein kinase CK2 activity facilitates tumor necrosis factor- $\alpha$ mediated chondrocyte death through apoptosis and autophagy. PLoS One 6: e19163, 2011.

28. Hande KR: Etoposide: Four decades of development of a topoisomeraseII inhibitor. Eur J Cancer 34: 1514-1521, 1998.

29. Pommier Y, Pourquier P, Fan Y and Strumberg D: Mechanism of action of eukaryotic DNA topoisomerase I and drugs targeted to the enzyme. Biochim Biophys Acta 1400: 83-105, 1998.

30. Debatin KM, Poncet D and Kroemer G: Chemotherapy: targeting the mitochondrial cell death pathway. Oncogene 21: 8786-8803, 2002.

31. Park JW, Choi YJ, Suh SI, Baek WK, Suh MH, Jin IN, Min DS, Woo JH, Chang JS, Passaniti A, Lee YH and Kwon TK: Bcl-2 overexpression attenuates resveratrol-induced apoptosis in U937 cells by inhibition of caspase-3 activity. Carcinogenesis 22: 1633-1639, 2001

32. Lee JS, Jeong SH, Soung YH, Kim TH, Choi HJ, Park BS, Kwon TK and Yoo YH: SAHA treatment overcomes the antiapoptotic effects of Bcl-2 and is associated with the formation of mature PML nuclear bodies in human leukemic U937 cells. Chem Biol Interact 18: 61-70, 2009.

33. Han W, Li S, Qiu S, Lu Q, Pan Q, Gu Y, Luo J and Hu X: Shikonin circumvents cancer drug resistance by induction of a necroptotic death. Mol Cancer Ther 6: 641-649, 2007.

34. Stendel R, Biefer HR, Dékány GM, Kubota H, Münz C, Wang S, Mohler H, Yonekawa Y and Frei K: The antibacterial substance taurolidine exhibits anti-neoplastic action based on a mixed type of programmed cell death. Autophagy 5: 194-210, 2009.

35. Tomic T, Botton T, Cerezo M, Robert G, Luciano F, Puissant A, Gounon P, Allegra M, Bertolotto C, Bereder JM, TartareDeckert S, Bahadoran P, Auberger P, Ballotti R and Rocchi S: Metformin inhibits melanoma development through autophagy and apoptosis mechanisms. Cell Death Dis 2: e199, 2011.

36. Koff A, Giordano A, Desai D, Yamashita K, Harper JW, Elledge S, Nishimoto T, Morgan DO, Franza BR and Roberts JM: Formation and activation of a cyclin E-cdk2 complex during the G1 phase of the human cell cycle. Science 257: 1689-1694, 1992.

37. Elledge SJ and Harper JW: Cdk inhibitors: on the threshold of checkpoints and development. Curr Opin Cell Biol 6: 847-852, 1994.

38. Sidle A, Palaty C, Dirks P, Wiggan O, Kiess M, Gill RM, Wong AK and Hamel PA: Activity of the retinoblastoma family proteins, $\mathrm{pRB}, \mathrm{p} 107$, and $\mathrm{p} 130$, during cellular proliferation and differentiation. Crit Rev Biochem Mol Biol 31: 237-271, 1996.

39. Sandal T: Molecular aspects of the mammalian cell cycle and cancer. Oncologist 7: 73-81, 2002.

40. Knudsen KE, Booth D, Naderi S, Sever-Chroneos Z, Fribourg AF, Hunton IC, Feramisco JR, Wang JY and Knudsen ES: RB-dependent S-phase response to DNA damage. Mol Cell Biol 20: 7751-776, 2000.

41. Li M, Jiang X, Liu D, Na Y, Gao GF and Xi Z: Autophagy protects $\mathrm{LNCaP}$ cells under androgen deprivation conditions. Autophagy 4: 54-60, 2008

42. Zhou F, Yang Y and Xing D: Bcl-2 and Bcl-xL play important roles in the crosstalk between autophagy and apoptosis. FEBS J 278: 403-413, 2011.

43. Ciechomska IA, Goemans GC, Skepper JN and Tolkovsky AM: Bcl-2 complexed with beclin-1 maintains full anti-apoptotic function. Oncogene 28: 2128-214, 2009. 